\title{
28 Research Square \\ Isolation and Molecular Identification of Respiratory Diseases Viruses in Poultry During 2020
}

\author{
Nahed Yehia \\ Cairo University

\section{Fatma Amer} \\ Cairo University \\ Abdelhafez Samir \\ Cairo University \\ Mohamed Samy \\ Cairo University \\ Ahmed Sedeek \\ Cairo University \\ Neveen Rebie \\ Cairo University \\ Wafaa Mohammed \\ Cairo University
}

\section{Salama Mostafa Aboelenin}

Taif University

Mohamed M. Soliman

Taif University

Mohamed T. El-Saadony ( $\square$ m.talaatelsadony@gmail.com )

Zagazig University

Naglaa Hagag

Cairo University

Original article

Keywords: Respiratory disease, HPAIV (H5N8), LPAIV (H9N2), IBV, Genetic characterization

Posted Date: July 13th, 2021

DOI: https://doi.org/10.21203/rs.3.rs-694718/v1

License: (9) This work is licensed under a Creative Commons Attribution 4.0 International License.

Read Full License 


\section{Abstract}

Poultry production has affected by multiple respiratory disease triggering serious economic losses in Egypt. In this study, the situation and genetic evolution of respiratory disease in Egypt during 2020 were studied. We collected 53 samples from infected flocks suffered from respiratory signs and variable mortality rate from nine governorates in Egypt during 2020. The collected samples were examined for detection of respiratory disease viruses (Avian influenza virus (AIV), Infectious bronchitis virus (IBV), and Newcastle disease virus (NDV)) by rRT-PCR. The single infection was confirmed in $90.6 \%(37.7 \% \mathrm{l}$. B, $30.2 \%$ AIV (H5N8), 9.4\% I. B and 5.7\% NDV) and co-infection of HPAIV (H5N8) + I.BV and LPAIV (H9N2) +IBV were detected in $3.8 \%$ in nine governorates. The HA gene of HPAIV (H5N8) were cluster to clad 2.3.4.4.1b in new branch with characteristic specific mutations especially in T140A in antigenic site $A$ and R72S in the receptor binding site when comparing with A/duck/Egypt/F446/2017 with low A.A identity percent with vaccinal strains (H5N1 and H5N2) reach to $91.9-94 \%$ and $84.6 \%$ respectively. The HA gene of AIV (H9N2) were belong to A/quail/Hong Kong/G1/97-like virus clustered with group B with specific mutation (212I) that may be effect on human transmission of the virus. The HVRs of S1 gene of IBV cluster to GI23 (Egy Var I) clad with multiple mutation in HVR1, HVR2 when comparing with IBV/CU/4/2014 and low identity percent (68.3\%-78.8\%) with vaccine strains (H120, M41, 4/91). In conclusion, the respiratory disease continues circulate and rapidly evolved in Egypt during 2020.

\section{Introduction}

The poultry industry is one of the most significant industries impacting the national economy in Egypt by promoting investment and jobs availability. Moreover, the primary sources of inexpensive animal protein for poor people in Egypt are poultry meat and eggs (Abdelwhab and Hafez 2011). Regrettably, mainly viral respiratory diseases have affected the poultry industry in Egypt for several years (Awad et al. 2016; Haghighat-Jahromi et al. 2008; Hassan et al. 2021; ME 2014). The inability to control of this disease results in significant economic losses in the poultry sector. The avian influenza (highly pathogenic, Low Pathogenic), Newcastle disease virus (NDV) and infectious bronchitis virus (IBV) alone or with mixed infection with each other or with other bacterial infection are the main cause of respiratory disease affect poultry farm with high mortality rate (Hassan et al. 2016; Radwan et al. 2013; Samy and Naguib 2018). Avian influenza (Al) was the most severe respiratory disease in Egypt. The highly pathogenic avian influenza (HPAl) H5N8 was first recorded in 2016 from wild bird (Selim et al. 2017) then observed in domestic birds causing severe losses in poultry production (Anis et al. 2018; Salaheldin et al. 2018; Yehia et al. 2018). Until now is still circulating as single or co-infection with other respiratory viruses (Hassan et al. 2021; Shehata et al. 2019; Yehia et al. 2018). The low pathogenic avian influenza (LPAl) H9N2 was first recorded in 2010- 2011 and it is belonging to G1 lineage (El-Zoghby et al. 2012). As mainly observed co-infection with H9N2 and I.B viruses, it has immunosuppressive effects that lead to increased opportunism of the infection by other viral and bacterial diseases (Hassan et al. 2017). In addition, the co-infection with other bacterial infection as Escherichia coli and Haemophilus paragallinarum contribute to increase the virulence of H9N2 because it has endo proteases enzyme that cleavage 
precursor HA proteins (Haghighat-Jahromi et al. 2008; Hassan et al. 2017; Pan et al. 2012). IBV that causing air saculitis in chickens is one of the major significant respiratory infections (S. Hofstad 1984). It is primarily recorded in Egypt in 1950s (Sheble et al. 1986) that related to the Dutch variant D3128 then D274, Mass, 4/91 and D-08880 (Eid 1998). Novel endemic genotypes associated with Israeli variant 2 and mass serotypes were detected in 2006 (Abdel-Moneim et al. 2006b). In 2011, the Egyptian virus mutated and classified into variant I and variant II (Abdel-Moneim et al. 2012). The both types of IBV virus circulated in Egypt causing outbreaks despite of vaccination program led to high economic losses (Abd El Rahman et al. 2015; Zanaty et al. 2016). The most severe respiratory disease is Newcastle disease (ND) that causing high mortality in poultry flocks (OIE 2012). In Egypt, the NDV first recorded in 1948 (Daubney and Mansy 1948) then spread rapidly in Egypt despite of vaccination programs (Abdel-Moneim et al. 2006a; El-Bagoury et al. 2015). Virus isolation is the fundamental diagnostic test for avian respiratory viruses, but it appears to be expensive, slow, and labor-intensive (Suarez et al. 2007). Recently, reverse transcriptase polymerase chain reaction (RT-PCR) and real-time RT-PCR (rRT-PCR) were rapid diagnostic tests used to detect viral nucleic acid (Spackman et al. 2002). The aim of our research is to explore the situation of respiratory disease outbreaks in Egypt during 2020 using rRT-PCR and genetically characterized the selected circulating respiratory viruses.

\section{Materials And Methods}

\section{Collection and preparation of specimens}

In this study, AIV (H5N8 and H9N2), NDV and IBV were examined for 53 infected poultry flocks exhibiting severe respiratory manifestation and high mortality during 2020. The oropharyngeal swabs were obtained from disease or freshly dead birds in nine provinces of Egypt including Alexandria, Giza, Dakhalia, El-sharqia, Qualiobia, El-Monofia, El-Behira, Domiat and Cairo (Table 1, Fig. 1). 45 chicken flocks were included in the samples ( 36 broilers, 5 commercial layers and 4 breeder farms), two flock of turkeys and6 duck farms. From each flock, 10 to 15 swabs were pooled in $2 \mathrm{ml}$ of phosphate buffer saline (PBS) (Naguib et al. 2017; OIE 2014).

\section{RNA extraction, identification and subtyping of viruses}

The QIAamp Viral RNA Mini Kit (Qiagen) using for extraction of viral RNA from pooled oropharyngeal swabs as directed by the manufacturer, then eluted into $50 \mu$ of nuclease-free water. All samples were tested for detection of $\mathrm{M}$ gene of influenza type A viruses by rRT-PCR (Fereidouni et al. 2012) using the AgPath Real-time Kit (Ambion) and the real-time PCR step one plus System (Applied Biosystems, Foster City, CA, USA). Then subtyping using rRT-PCR target HA and NA genes as described by Hoffmann et al. (2016).In addition, all samples were tested for detection of NDV, IBV using rRT-PCR target matrix gene of avian paramyxovirus ${ }^{-1}$ (Wise et al. 2004) then the positive samples were tested for the detection of NDV of genotype VII d (velogenic strain) (Moharam et al. 2019). Also, rRT-PCR was used for detection IBV RNA as described by Naguib et al. (2017). 


\section{Virus isolation}

The positive samples were isolated into SPF embryonated chicken eggs (ECEs) 10 days old in allontoic fluid with daily observation. The mortalities were recorded and allonotic sac was collected and tested by rapid slide hemagglutination (HA) test (OIE 2008).

\section{Sequencing of the viral genome}

The HA gene of $\mathrm{Al}(\mathrm{H} 5, \mathrm{H} 9)$ and HVRs of S1 gene of IBV amplification were carried out by PCR using specific primers as described by Höper et al. (2009); Naguib et al. (2015); Suarez et al. (2007) and high fidelity Phusion ${ }^{\circledR}$ DNA polymerase (Thermo Fisher Scientific, MA, USA). Using QIA quick Gel Extraction Kit, the PCR products were separated and purified from gel (Qiagen). Cycle sequencing reactions have been performed on PCR products using BigDye Terminator v3.1 Cycle Sequencing Kit (Applied Biosystems). Using centri-sep columns (Macherey-Nagel GmbH \& Co.) the sequence products were purified then sequenced on an ABI PRISM3130 Genetic Analyzer (Life Technologies). For each sequence the blast search was performed (http://www.ncbi.nlm.nih.gov/BLAST). Mutation and phylogenetic analysis were conducted using MEGA version 6 program using bootstrap of 1,000 trials of clustal W alignment algorithm (Tamura et al. 2013). The amino acid identity was carried out using DNA star software (DNAStar, Madison, WI). Then published by the national center for Biotechnology Information (NCBI) with accession number provided in Table 2.

\section{Results}

\section{Real time-PCR}

The 48 samples/ 53 were positive for RT-PCR for different respiratory disease (twenty samples were positive for IBV, sixteen samples for HPAI (H5N8), five samples for LPAI (H9N2), three samples for NDV (velogenic strain), two samples for HPAI (H5N8) +IBV and two samples for LPAI (H9N2) + I.BV as mentioned in Table.1.

\section{Genetic characterization of the HPAl (H5N8) Virus HA gene}

Phylogenetic analysis of full HA sequence of a four selected Al (H5N8) isolate was named $\mathrm{A} /$ CHICKEN/EGYPT/FN1/2020, A/ CHICKEN/EGYPT/FN2/2020 from co-infected farms and A/ CHICKEN/EGYPT/FN3/202, CHICKEN/EGYPT/FN4/2020 from other infected flocks were belong to clade 2.3.4.4b. They cluster with Egyptian viruses isolated in 2019 making new branch with bootstrapping 95 as showed in Fig.1. They have 5 nucleotide mutations when comparing with A/duck/Egypt/F446/2017 different from Egyptian viruses isolated in 2017 and 2018. By mutation analysis, in antigenic site $A$, one mutation (T140A) was detected in the A/chicken/Egypt/FN1/2020 and A/chicken/Egypt/FN2/2020 similar to A/Chicken/Egypt/186FL/2018. In addition, the receptor-binding site in A/chicken/Egypt/FN3/2020 had R72S similar to A/Chicken/Egypt/185/2018 and A/Chicken/Egypt/186FL/2018. The S94R also found only in the A/chicken/Egypt/FN3/2020. The A.A. 
identity of our strains and H5N1 vectoremune vaccine (A/mute_swan/Hungary/4999/2006), B.E.S.T Vaccine (A/duck/China/E319-2/03) ranged from 91.9-94\% and H5N2 CEVac Flukem (A/chicken/Mexico/232/1994) was 84.6\% (Fig.2).

\section{Genetic characterization of the H9N2 Virus HA gene}

The phylogenetic analysis of full HA sequence of three selected Al H9 isolate was named A/ CHICKEN/EGYPT/FW1/2020 from co-infected farms and A/ CHICKEN/EGYPT/FW2/2020 and A/ CHICKEN/EGYPT/FW3/2020 from single infected flocks was belonged to the A/quail/Hong Kong/G1/97like virus lineage clustered with group B (Fig.3). The viruses in our study were closely related to other Egyptian strains with identities of 94.9-98.2\% (Fig.4). By mutation analysis we recorded mutation in S16N, M58K, T121I/V, I134M, T145S, N179T as specific to all Egyptian viruses and N41G, 175V, V212I, T413N resemble to Egyptian viruses in 2018-2019 when comparing with the A/quail/Hong Kong/G1/97. In addition, R180K/Q specific for viruses in this study. The amino acid sequences at the cleavage site of HA contained low pathogenic RSSR/GLF motif.

\section{Genetic characterization of S gene of I.B virus}

The phylogenetic analysis of HVRs of S1 genes of six selected viruses were named $\mathrm{IBV} / \mathrm{EGY} / \mathrm{CH} / \mathrm{AY} 1 / 2020$, IBV/EGY/CH/AY2/2020 and IBV/EGY/CH/AY3/2020 from co-infected flocks and $\mathrm{IBV} / \mathrm{EGY} / \mathrm{CH} / \mathrm{AY} 4 / 2020$, IBV/EGY/CH/AY5/2020 and IBV/EGY/CH/AY6/2020 from single infected flocks. The viruses in this study were cluster to clad GI23 (Egy Var I) (Fig.5).

By mutation analysis of HVRs, we recorded mutation in comparing with the reference strain IBV/CU/4/2014. The HVR1 had IBV-EGY-CH-AY1-2020, IBV-EGY-CH-AY2-2020, IBV-EGY-CH-AY3-2020 had 3 A.A. and IBV-EGY-CH-AY4-2020, IBV-EGY-CH-AY6-2020 had 4 A.A. and IBV-EGY-CH-AY5-2020 had 2 A.A. The HVRII had 7A.A. mutation in all viruses except IBV-EGY-CH-AY2-2020 had 6 amino acid mutations and IBV-EGY-CH-AY1-2020, IBV-EGY-CH-AY5-2020 had 4 A.A. as shown in Fig.6. The S1 gene identity of amino acids revealed that our viruses relate to vaccine seeds used commonly in Egypt (M41, H120,4/91) ranging from $68.3 \%-78.8 \%$ as shown in Fig.7.

\section{Discussion}

In Egypt during the last years, the outbreaks due to respiratory disease with high mortality rates has increased and effect on the poultry production in Egypt. Many avian viral pathogens were the main cause of this problem (Malik et al. 2004; Roussan et al. 2008). The avian influenza virus (HP, LP), IBV and NDV were the main detected viruses alone or as co-infected in broiler chicken (Hassan et al. 2016). The aim of this study was to identify the incidence of viral respiratory disease in broiler chicken especially AIV (HP, LP), IBV and NDV in Egypt during 2020 and study the molecular characterization and evolution of detected viruses. In this study, multiple respiratory viruses as single or mixed infection were detected. The AIV subtypes and IBV recorded in 48 out of 53 farms. Single infection represented only $90.6 \%$ (37.7\% I.B, $30.2 \% \mathrm{H} 5 \mathrm{~N} 8,9.4 \%$ I.B and 5.7\% NDV). Also, co-presence of HPAI (H5N8) and IBV that is unique detection 
of these co-infected flocks and LPAI (H9N2) and IBV were detected in 3.8\% as previously recorded in ElShall et al. (2019). The occurrence of IBV and HPAI (H5N8) in Egyptian poultry with high mortality rate in different vaccinated poultry flocks has previously been reported (Abd El Rahman et al. 2015; AbdelMoneim et al. 2006a; Yehia et al. 2020).

In recent years, the avian influenza situation in Egypt has been more complicated due to detection and circulation of many serotypes HPAI (H5N1) and HPAI (H5N8) and LPAI (H9N2) (Shehata et al. 2019). The phylogenetic analysis of four selected samples of HA gene of HPAI H5N8 revealed that the four samples were cluster to clad 2.3.4.4.1b as previously recorded in (El-Shall et al. 2019; Shehata et al. 2019) in new branch with characteristic specific mutations. By mutation analysis we detect change in the (T140A) antigenic site $A$ in two samples A/chicken/Egypt/FN1/2020 and A/chicken/Egypt/FN2/2020 as previously recorded in 43 that may be due to excessive using of avian influenza vaccine H5N1 and H5N2. In addition, the R72S in A/chicken/Egypt/FN3/2020 in the receptor binding site was detected as previously recorded in Nabil et al. (2020). We need further study to detect the effect of mutation in the virulence of H5N8 virus. The A.A. identity was very low in H5N1 and H5N2 vaccine reach to $91.9-94 \%$ and $84.6 \%$ respectively as previously recorded (Kandeil et al. 2018; Yehia et al. 2020). It was explained where the outbreaks occurred in the vaccinated flocks and causing high mortality. Further study needs for evaluation the protective efficacy of the vaccines and prepare autogenus vaccine that may be more effective against HPAI H5N8. The phylogenetic analysis of three selected strains from single and coinfected flocks reveal that all viruses in our study belong to A/quail/Hong Kong/G1/97-like virus lineage clustered with group B as previously recorded (Hassan et al. 2016; Yang et al. 2017) with six A.A. mutation specific for Egyptian viruses. In addition, 175V, N41G and T413N mutation specific to 20182019 Egyptian viruses and the 212I mutation that has important effect on increased the pathogenicity of the H9N2 in mice as previously recorded in Abozeid et al. (2017). We need further studied to study their effect on the pathogenicity of the virus. In this study, we recorded high number of infected vaccinated flocks with IBV viruses by RT-PCR but it does not distinguish between field and vaccine strains of IBV. So partial S1 gene sequencing is important to identify the IBV strains. Furthermore, the partial IBV S1 gene was sequenced and analyzing reveal that six selected viruses of single and co-infected I.B were related to clad GI23 (Egy Var I) clad as previously recorded (Hassan et al. 2016; Zanaty et al. 2016) with low identity percent with vaccine strains $\mathrm{H} 120, \mathrm{M} 41,4 / 91$ ranging from $68.3 \%-78.8 \%$ that lead to appearance of infection in vaccinated farms as previously recorded (Abd El Rahman et al. 2015; Sultan et al. 2019). We need further study to evaluate vaccine efficacy and update the vaccine use to give highly protection against newly mutated strains.

The S1 subunit, which comprises three major hyperactive variable regions (HVRs) in the first 395 amino acid. The HVRs contain major antigenic sites between 38 to 67 amino acid (HVR-1), 97 to 141 amino acid (HVR2), and 274 to 387 amino acid (HVR-3) (Moore et al. 1997). In our study, we recorded multiple A.A. mutation in the HVR as previously recorded (Abozeid et al. 2017; Hassan et al. 2017; Zanaty et al. 2016) that may be due to widespread using of heterologous vaccine that led to vaccination pressure. It results in the increase the pathogenesis of the virus and change of tissue tropism (Cavanagh et al. 1992). In conclusion IBV and HPAIV (H5N8) are the main causes of respiratory disease in Egypt alone or co- 
infected with other viruses with high mortality rate. Circulation of Al (H5N8) was detected with mutation in the antigenic site and receptor binding site, LPAI (H9N2) with specific mutation and IBV viruses were rapidly evolved in HVRS. the IBV and HPAI H5N8 viruses was distinct from vaccine strains so it is important to surveillance of respiratory disease viruses and study the genetic evolution and its effect on pathogenicity and vaccine efficacy.

\section{Abbreviations}

AIV: Avian influenza virus; IBV: Infectious bronchitis virus; NDV: Newcastle disease virus; RT-PCR: Reverse transcription polymerase chain reaction; Al: Avian influenza; HPAl: Highly pathogenic avian influenza; LPAI: Low pathogenic avian influenza; rRT-PCR: real-time reverse transcription polymerase chain reaction; PBS: Phosphate buffer saline; HVRs: hyperactive variable regions.

\section{Declarations}

\section{Acknowledgements}

Taif University Researchers Supporting Project number (TURSP-2020/220), Taif University, Taif, Saudi Arabia.

\section{Authors' contribution}

M.S. was carried out collection of samples from the affected flocks, F. A., A. S. were carried out detection of the DNA of respiratory diseases by RT-PCR. A. S. carried out isolation of samples in SPF ECE. N. Y., N. $\mathrm{H}$. were carried out the sequencing, Genetic and phylogenetic Analysis and analysis of the data and writing the manuscript. W. M. supervised and final revision of the manuscript. S. M. A., M. M. S., M. T. E.S. provided technical help in writing the manuscript. The all authors read and approved final manuscript.

\section{Conflict of interest}

Authors declare that they have no conflict of interest.

\section{Funding}

The current work was funded by Taif University, Saudi Arabia, for financial support through its Researchers Supporting Project (TURSP-2020-105).

\section{Availability of data and materials}

All data generated or analyzed during this study are included in this published article.

\section{Ethics approval and consent to participation}

The authors confirm that the ethical policies of the journal, as noted on the journal's author guidelines page, have been adhered to and the appropriate ethical review committee approval has been received. 
The authors confirm that they have followed EU standards for the protection of animals used for scientific purposes.

\section{Consent for publication}

Not applicable.

\section{Competing interests}

The authors declare no competing interests.

\section{References}

1. Abd El Rahman S, Hoffmann M, Lueschow D, Eladl A, Hafez H (2015) Isolation and characterization of new variant strains of infectious bronchitis virus in Northern Egypt. Adv Anim Vet Sci 3:362-371

2. Abdel-Moneim A, El-Sawah AA, Kandil M (2006a) Characterization of variant strain of Newcastle disease virus in Egypt. Journal of Veterinary Medical Research 16(1):12-17

3. Abdel-Moneim AS, Afifi MA, El-Kady MF (2012) Emergence of a novel genotype of avian infectious bronchitis virus in Egypt. Archives of virology 157(12):2453-2457

4. Abdel-Moneim AS, El-Kady MF, Ladman BS, Gelb J (2006b) S1 gene sequence analysis of a nephropathogenic strain of avian infectious bronchitis virus in Egypt. Virology journal 3(1):1-9

5. Abdelwhab E, Hafez H (2011) An overview of the epidemic of highly pathogenic H5N1 avian influenza virus in Egypt: epidemiology and control challenges. Epidemiology \& Infection 139(5):647657

6. Abozeid HH, Paldurai A, Khattar SK, Afifi MA, El-Kady MF, El-Deeb AH, Samal SK (2017) Complete genome sequences of two avian infectious bronchitis viruses isolated in Egypt: evidence for genetic drift and genetic recombination in the circulating viruses. Infection, Genetics and Evolution 53:7-14

7. Anis A, AboElkhair M, Ibrahim M (2018) Characterization of highly pathogenic avian influenza H5N8 virus from Egyptian domestic waterfowl in 2017. Avian pathology 47(4):400-409

8. Awad AM, Ali AB, El-Hamid HSA, El-Naggar AL, Sediek ME, El-Shall NA, El-Samahy HS (2016) Epidemiological Studies on H5N1 and H9N2 Avian Influenza Viruses during late 2013 and 2015 in Egypt. Alexandria Journal for Veterinary Sciences 51(2)

9. Cavanagh D, Davis P, Cook J (1992) Infectious bronchitis virus: evidence for recombination within the Massachusetts serotype. Avian Pathology 21(3):401-408

10. Daubney R, Mansy W (1948) The occurrence of Newcastle disease in Egypt. Journal of Comparative Pathology and Therapeutics 58:189-200

11. Eid A Infectious bronchitis virus infection in Egypt. In: Proceedings of the International Symposium on Infectious Bronchitis and Pneumovirus Infections in Poultry Rauischholzhausen, Germany, 1998. p 145-156 
12. El-Bagoury GF, El-Habbaa AS, El-Adaway SF, El-Mahdy SS (2015) Isolation, identification and pathotyping of Newcastle disease virus from chickens in Egypt. Benha veterinary medical journal 29(1):196-204

13. El-Shall NA, Sedeik ME, El-Nahas AF, Abdel-salam RA, Awad AM (2019) Epidemiological Surveillance of Some Avian Respiratory Viral Diseases in Broiler Chickens. Alexandria Journal for Veterinary Sciences 61(1)

14. El-Zoghby EF, Arafa A-S, Hassan MK, Aly MM, Selim A, Kilany WH, Selim U, Nasef S, Aggor MG, Abdelwhab E (2012) Isolation of H9N2 avian influenza virus from bobwhite quail (Colinus virginianus) in Egypt. Archives of virology 157(6):1167-1172

15. Fereidouni SR, Harder TC, Gaidet N, Ziller M, Hoffmann B, Hammoumi S, Globig A, Starick E (2012) Saving resources: avian influenza surveillance using pooled swab samples and reduced reaction volumes in real-time RT-PCR. Journal of virological methods 186(1-2):119-125

16. Haghighat-Jahromi M, Asasi K, Nili H, Dadras H, Shooshtari A (2008) Coinfection of avian influenza virus (H9N2 subtype) with infectious bronchitis live vaccine. Archives of virology 153(4):651-655

17. Hassan KE, Ali A, Shany SA, El-Kady MF (2017) Experimental co-infection of infectious bronchitis and low pathogenic avian influenza H9N2 viruses in commercial broiler chickens. Research in veterinary science 115:356-362

18. Hassan KE, El-Kady MF, EL-Sawah AA, Luttermann C, Parvin R, Shany S, Beer M, Harder T (2021) Respiratory disease due to mixed viral infections in poultry flocks in Egypt between 2017 and 2018: Upsurge of highly pathogenic avian influenza virus subtype H5N8 since 2018. Transboundary and emerging diseases 68(1):21-36

19. Hassan KE, Shany SA, Ali A, Dahshan A-HM, Azza A, El-Kady MF (2016) Prevalence of avian respiratory viruses in broiler flocks in Egypt. Poultry science 95(6):1271-1280

20. Hoffmann B, Hoffmann D, Henritzi D, Beer M, Harder TC (2016) Riems influenza a typing array (RITA): an RT-qPCR-based low density array for subtyping avian and mammalian influenza a viruses. Scientific reports 6(1):1-10

21. Höper D, Hoffmann B, Beer M (2009) Simple, sensitive, and swift sequencing of complete H5N1 avian influenza virus genomes. Journal of clinical microbiology 47(3):674-679

22. Kandeil A, Sabir JS, Abdelaal A, Mattar EH, El-Taweel AN, Sabir MJ, Khalil AA, Webby R, Kayali G, Ali MA (2018) Efficacy of commercial vaccines against newly emerging avian influenza H5N8 virus in Egypt. Scientific reports 8(1):1-6

23. Malik YS, Patnayak DP, Goyal SM (2004) Detection of three avian respiratory viruses by single-tube multiplex reverse transcription-polymerase chain reaction assay. Journal of veterinary diagnostic investigation 16(3):244-248

24. ME S (2014) Molecular characterization and serotyping of infectious bronchitis viruses isolated from broiler chicken farms in Egypt during 2013.

25. Moharam I, Razik AAe, Sultan H, Ghezlan M, Meseko C, Franzke K, Harder T, Beer M, Grund C (2019) Investigation of suspected Newcastle disease (ND) outbreaks in Egypt uncovers a high virus 
velogenic ND virus burden in small-scale holdings and the presence of multiple pathogens. Avian Pathology 48(5):406-415

26. Nabil NM, Erfan AM, Tawakol MM, Haggag NM, Naguib MM, Samy A (2020) Wild birds in live birds markets: Potential reservoirs of enzootic avian influenza viruses and antimicrobial resistant enterobacteriaceae in northern Egypt. Pathogens 9(3):196

27. Naguib MM, Arafa A-SA, El-Kady MF, Selim AA, Gunalan V, Maurer-Stroh S, Goller KV, Hassan MK, Beer M, Abdelwhab E (2015) Evolutionary trajectories and diagnostic challenges of potentially zoonotic avian influenza viruses H5N1 and H9N2 co-circulating in Egypt. Infection, Genetics and Evolution 34:278-291

28. Naguib MM, El-Kady MF, Lüschow D, Hassan KE, Arafa A-S, El-Zanaty A, Hassan MK, Hafez HM, Grund C, Harder TC (2017) New real time and conventional RT-PCRs for updated molecular diagnosis of infectious bronchitis virus infection (IBV) in chickens in Egypt associated with frequent coinfections with avian influenza and Newcastle disease viruses. Journal of virological methods 245:19-27

29. OIE (2012) Newcastle disease. Manual of Diagnostic Tests and Vaccines for Terrestrial Animals. Chapter 2314 http://wwwoieint/ international-standardsetting/terrestrial-manual/access-online

30. OIE (2014) chapter 2.3.4. Manual of Diagnostic Tests and Vaccines for Terrestrial Animals. Avian influenza Accessed Nov 2015

31. OIE M (2008) Update on highly pathogenic avian influenza in animals (type H5 and H7).465-476

32. Pan Q, Liu A, Zhang F, Ling Y, Ou C, Hou N, He C (2012) Co-infection of broilers with Ornithobacterium rhinotracheale and H9N2 avian influenza virus. BMC veterinary research 8(1):1-7

33. Radwan M, Darwish S, El-Sabagh I, El-Sanousi A, Shalaby M (2013) Isolation and molecular characterization of Newcastle disease virus genotypes II and VIId in Egypt between 2011 and 2012. Virus genes 47(2):311-316

34. Roussan D, Haddad R, Khawaldeh G (2008) Molecular survey of avian respiratory pathogens in commercial broiler chicken flocks with respiratory diseases in Jordan. Poultry science 87(3):444-448

35. S. Hofstad HJB, B. W. Calnek, W. M. Reid, and H. W. Yoder (1984) Avian infectious bronchitis. lowa State University Press: Ames, IA

36. Salaheldin AH, Abd El-Hamid HS, Elbestawy AR, Veits J, Hafez HM, Mettenleiter TC, Abdelwhab EM (2018) Multiple introductions of influenza A (H5N8) virus into poultry, Egypt, 2017. Emerging infectious diseases 24(5):943

37. Samy A, Naguib MM (2018) Avian respiratory coinfection and impact on avian influenza pathogenicity in domestic poultry: field and experimental findings. Veterinary sciences 5(1):23

38. Selim AA, Erfan AM, Hagag N, Zanaty A, Samir A-H, Samy M, Abdelhalim A, Arafa A-SA, Soliman MA, Shaheen M (2017) Highly pathogenic avian influenza virus (H5N8) clade 2.3. 4.4 infection in migratory birds, Egypt. Emerging infectious diseases 23(6):1048

39. Sheble A, Sabry M, Davelaar F, Burger A, Khafagy A, Moustafa F, Moustafa M, Henna M (1986) Present status of infectious bronchitis in Egypt. J Egyp Vet Med Assoc 4:393-411 
40. Shehata AA, Sedeik ME, Elbestawy AR, El-Abideen MAZ, Ibrahim HH, Kilany WH, Ali A (2019) Coinfections, genetic, and antigenic relatedness of avian influenza H5N8 and H5N1 viruses in domestic and wild birds in Egypt. Poultry science 98(6):2371-2379

41. Spackman E, Senne DA, Myers T, Bulaga LL, Garber LP, Perdue ML, Lohman K, Daum LT, Suarez DL (2002) Development of a real-time reverse transcriptase PCR assay for type A influenza virus and the avian $\mathrm{H} 5$ and $\mathrm{H} 7$ hemagglutinin subtypes. Journal of clinical microbiology 40(9):3256-3260

42. Suarez DL, Das A, Ellis E (2007) Review of rapid molecular diagnostic tools for avian influenza virus. Avian diseases 51(s1):201-208

43. Sultan HA, Ali A, El Feil WK, Bazid AHI, Zain El-Abideen MA, Kilany WH (2019) Protective efficacy of different live attenuated infectious bronchitis virus vaccination regimes against challenge with IBV variant-2 circulating in the Middle East. Frontiers in veterinary science 6:341

44. Tamura K, Stecher G, Peterson D, Filipski A, Kumar S (2013) MEGA6: molecular evolutionary genetics analysis version 6.0. Molecular biology and evolution 30(12):2725-2729

45. Wise MG, Suarez DL, Seal BS, Pedersen JC, Senne DA, King DJ, Kapczynski DR, Spackman E (2004) Development of a real-time reverse-transcription PCR for detection of Newcastle disease virus RNA in clinical samples. Journal of clinical Microbiology 42(1):329-338

46. Yang W, Punyadarsaniya D, Lambertz R, Lee D, Liang C, Höper D, Leist SR, Hernández-Cáceres A, Stech J, Beer M (2017) Mutations during the adaptation of H9N2 avian influenza virus to the respiratory epithelium of pigs enhance sialic acid binding activity and virulence in mice. Journal of Virology 91(8):e02125-16

47. Yehia N, Hassan WM, Sedeek A, Elhusseiny MH (2020) Genetic variability of avian influenza virus subtype H5N8 in Egypt in 2017 and 2018. Archives of virology 165(6):1357-1366

48. Yehia N, Naguib MM, Li R, Hagag N, El-Husseiny M, Mosaad Z, Nour A, Rabea N, Hasan WM, Hassan MK (2018) Multiple introductions of reassorted highly pathogenic avian influenza viruses (H5N8) clade 2.3. $4.4 \mathrm{~b}$ causing outbreaks in wild birds and poultry in Egypt. Infection, genetics and evolution 58:56-65

49. Zanaty A, Arafa A-S, Hagag N, El-Kady M (2016) Genotyping and pathotyping of diversified strains of infectious bronchitis viruses circulating in Egypt. World journal of virology 5(3):125

\section{Tables}

Table (1) Epidemiological data of collected samples. FN: the table shows governorates, breeds, results of PCR of collected samples. 


\begin{tabular}{|c|c|c|c|}
\hline NO. & Governorates & Breed & Result \\
\hline 1 & El-Dakhlia & Broiler & HPAIV(H5N8) \\
\hline 2 & El-Dakhlia & Layer & HPAIV(H5N8) \\
\hline 3 & El-Dakhlia & Layer & IBV \\
\hline 4 & Giza & Breeder & IBV \\
\hline 5 & Alexandria & Duck & IBV \\
\hline 6 & Alexandria & Breeder & HPAIV(H5N8) \\
\hline 7 & Giza & Broiler & HPAIV(H5N8) \\
\hline 8 & Giza & Broiler & Negative \\
\hline 9 & Giza & Layer & HPAIV(H5N8) \\
\hline 10 & Giza & Broiler & NDV \\
\hline 11 & El-sharqia & Broiler & IBV \\
\hline 12 & El-Monofia & Broiler & NDV \\
\hline 13 & El-sharqia & Breeder & LPAIV(H9N2) \\
\hline 14 & El-Dakhlia & Broiler & IBV \\
\hline 15 & Cairo & Broiler & IBV \\
\hline 16 & Cairo & Layer & IBV \\
\hline 17 & Domiat & Layer & HPAIV(H5N8) \\
\hline 18 & El-Dakhlia & Broiler & IBV \\
\hline 19 & El-Dakhlia & Broiler & IBV \\
\hline 20 & El-Dakhlia & Breeder & HPAIV(H5N8) \\
\hline 21 & El-Behira & Duck & Negative \\
\hline 22 & Giza & Duck & IBV \\
\hline 23 & Beni-suief & Duck & IBV \\
\hline 24 & Beni-suief & Broiler & IBV \\
\hline 25 & El-Dakhlia & Broiler & IBV \\
\hline 26 & El-sharqia & Broiler & IBV \\
\hline 27 & Domiat & Broiler & IBV \\
\hline 28 & Domiat & Broiler & HPAIV(H5N8) \\
\hline
\end{tabular}

Page 12/21 


\begin{tabular}{|c|c|c|c|}
\hline 29 & Giza & Turkey & IBV \\
\hline 30 & Alexandria & Turkey & HPAIV(H5N8)+IBV \\
\hline 31 & Alexandria & Broiler & IBV \\
\hline 32 & Cairo & Broiler & IBV \\
\hline 33 & Cairo & Broiler & HPAIV(H5N8) \\
\hline 34 & El-Behira & Broiler & HPAIV(H5N8) \\
\hline 35 & Domiat & Broiler & Negative \\
\hline 36 & Giza & Broiler & LPAIV(H9N2) \\
\hline 37 & Giza & Broiler & IBV \\
\hline 38 & Beni-suief & Broiler & HPAIV(H5N8) \\
\hline 39 & El-Monofia & Duck & IBV \\
\hline 40 & El-Dakhlia & Duck & HPAI (H5N8) \\
\hline 41 & Cairo & Broiler & LPAIV(H9N2) \\
\hline 42 & El-sharqia & Broiler & IBV+LPAIV(H9N2) \\
\hline 43 & El-Monofia & Broiler & NDV \\
\hline 44 & Domiat & Broiler & HPAIV(H5N8) \\
\hline 45 & Domiat & Broiler & IBV+LPAIV(H9N2) \\
\hline 46 & El-sharqia & Broiler & HPAI (H5N8)+IBV \\
\hline 47 & El-Dakhlia & Broiler & HPAIV(H5N8) \\
\hline 48 & Beni-suief & Broiler & Negative \\
\hline 49 & Cairo & Broiler & HPAIV(H5N8) \\
\hline 50 & El-Behira & Broiler & HPAIV(H5N8) \\
\hline 51 & El-Dakhlia & Broiler & LPAIV(H9N2) \\
\hline 52 & El-Behira & Broiler & LPAIV(H9N2) \\
\hline 53 & El-sharqia & Broiler & Negative \\
\hline
\end{tabular}

Table (2) Accession number of sequenced samples. FN: the table shows accession numbers of HA gene of HPA I (H5N8 and H9N2) and S1 gene of IBV samples. 


\begin{tabular}{|c|c|c|c|c|}
\hline \multirow{2}{*}{ No. } & \multirow[t]{2}{*}{ Code } & \multicolumn{3}{|c|}{ GenBank Accession number } \\
\hline & & $\mathrm{HA}(\mathrm{H} 5)$ & $\mathrm{HA}(\mathrm{H} 9)$ & s1 \\
\hline 45 & IBV/EGY/CH/AY1/2020, A/chicken/FW1/2020 & - & MW227513 & MW240842 \\
\hline \multirow[t]{2}{*}{30} & IBV/EGY/CH/AY2/2020 & MW227501 & - & MW240843 \\
\hline & A/chicken/Egypt/FN1/2020 & & & \\
\hline 3 & IBV/EGY/CH/AY3/2020 & - & - & MW240844 \\
\hline 11 & IBV/EGY/CH/AY4/2020 & - & - & MW240845 \\
\hline 15 & IBV/EGY/CH/AY5/2020 & - & - & MW240846 \\
\hline 39 & $\mathrm{IBV} / \mathrm{EGY} / \mathrm{CH} / \mathrm{AY} 6 / 2020$ & - & - & MW240847 \\
\hline 13 & $\mathrm{~A} /$ chicken/FW2/2020 & - & MW227514 & - \\
\hline 36 & A/chicken/FW3/2020 & - & MW227515 & - \\
\hline 28 & A/chicken/Egypt/FN2/2020 & MW227502 & - & - \\
\hline 40 & A/chicken/Egypt/FN3/2020 & MW227503 & - & - \\
\hline
\end{tabular}

\section{Figures}




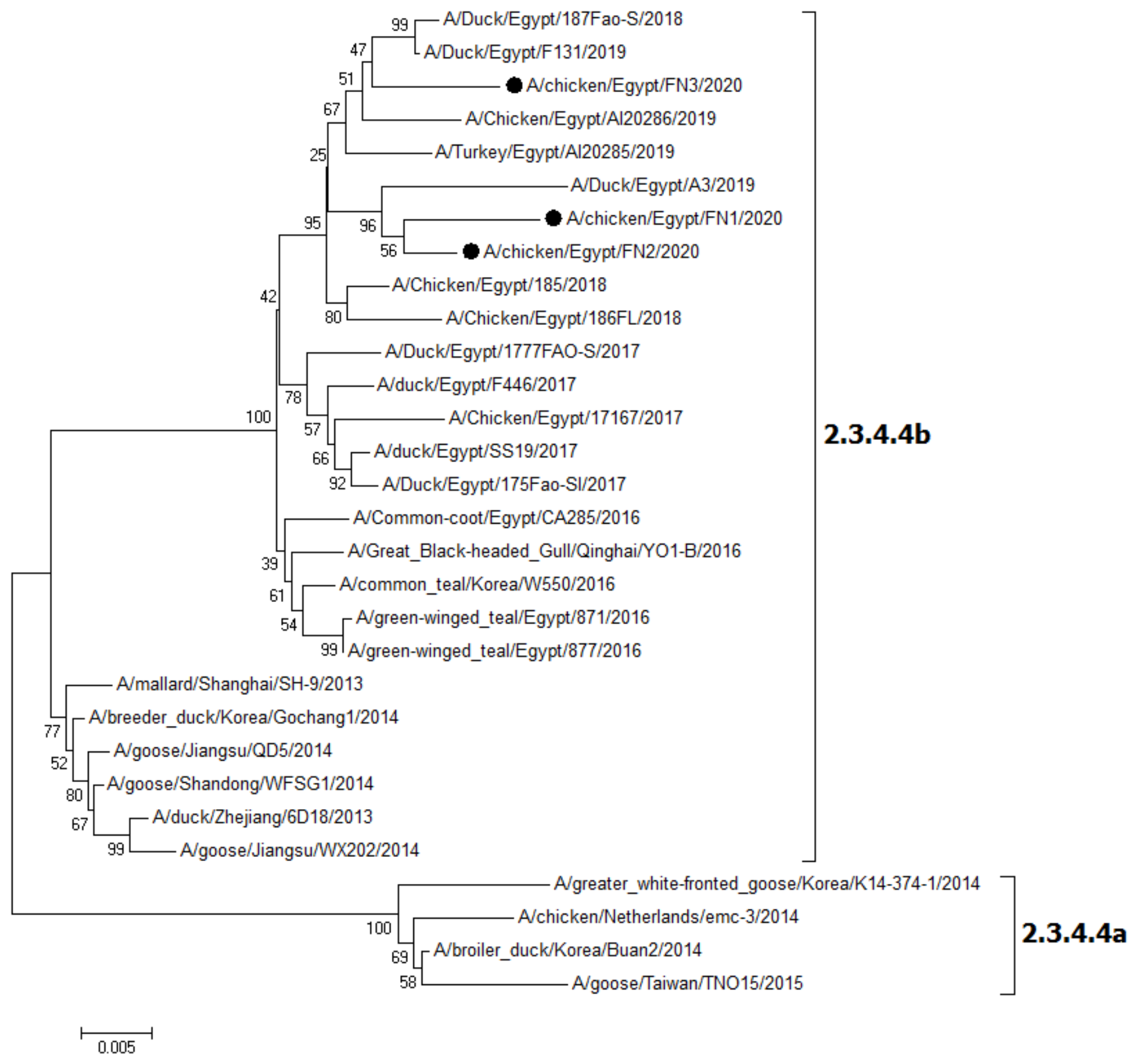

Figure 1

Phylogenetic tree of HA gene of H5N8. FN: The figure shows the phylogenetic analysis of HA gene of AIV H5N8 reveling that all Egyptian strains cluster were related 2.3.3.4b and begin to make new branch with H5N8 Egyptian viruses in 2019. The AI H5N8 viruses in our study are indicated with a black dot. 


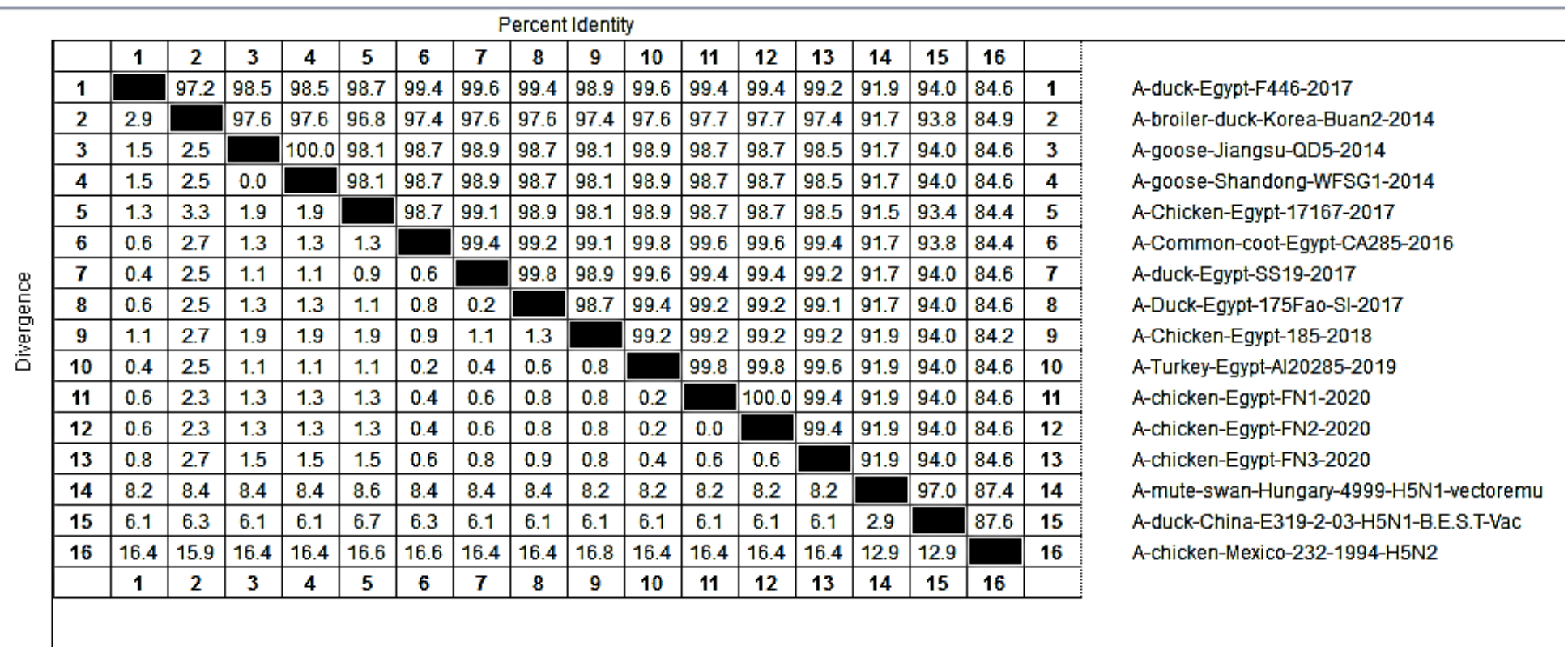

\section{Figure 2}

Amino acid identities and divergence of HA gene of H5N8 viruses compared to other selected strains and vaccinal strains. FN: Amino acid identity of HA gene of H5N8 viruses showed that A.A. identity percent of Egyptian $\mathrm{H} 5 \mathrm{~N} 8$ strain in this study ranged from $91.9-94 \%$ and $84.6 \%$ with $\mathrm{H} 5 \mathrm{~N} 1$ and $\mathrm{H} 5 \mathrm{~N} 2$ vaccine respectively. 


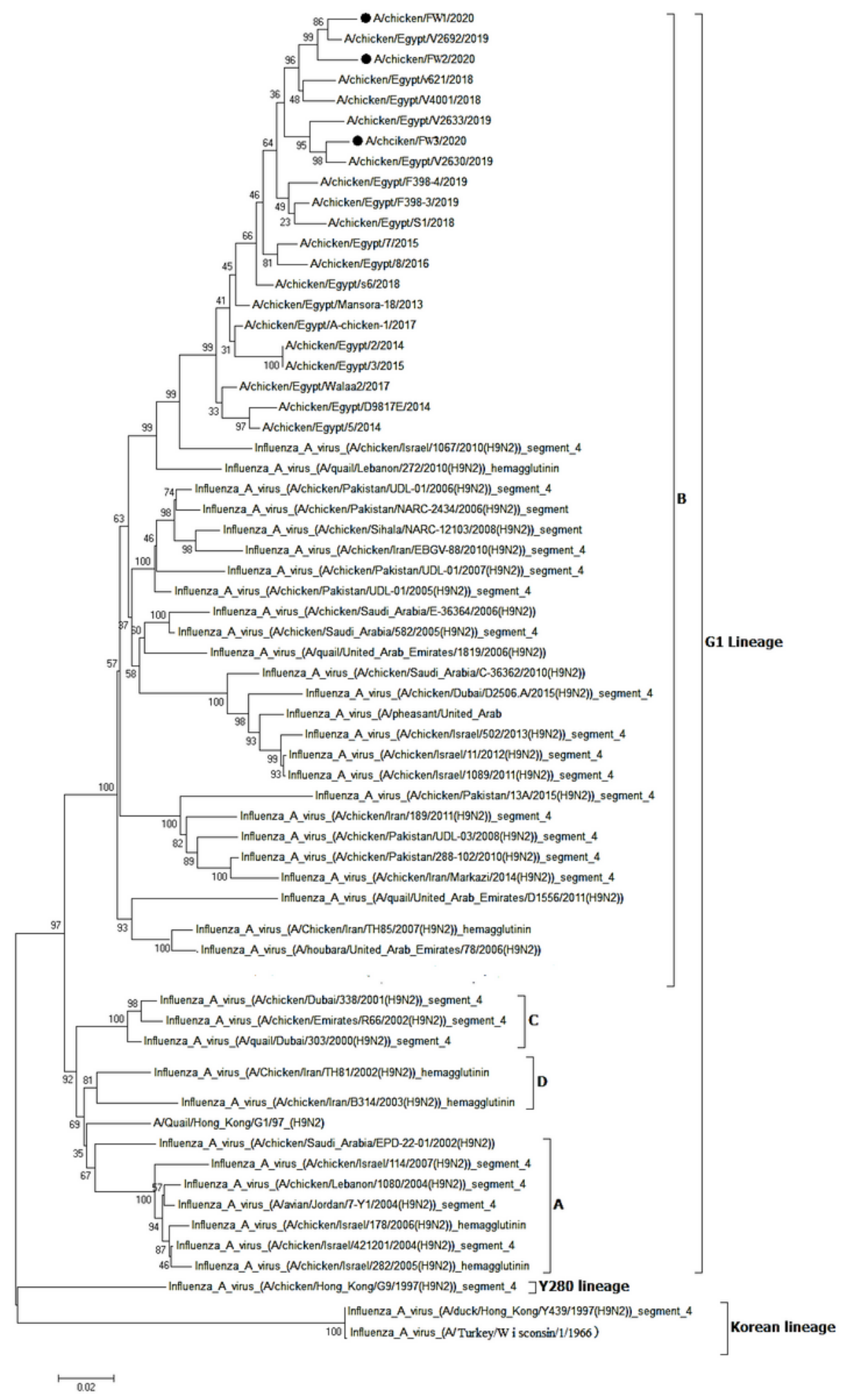

Figure 3

Phylogenetic tree of HA gene of H9N2. FN: The figure shows the phylogenetic analysis of HA gene of AIV H9N2 reveling that all Egyptian strains cluster were was belonged to the A/quail/Hong Kong/G1/97-like virus lineage clustered with group B. The Al H9N2 viruses in our study are indicated with a black dot. 
Percent Identity

\begin{tabular}{|c|c|c|c|c|c|c|c|c|c|c|c|c|c|c|c|c|c|c|c|c|}
\hline & 1 & 2 & 3 & 4 & 5 & 6 & 7 & 8 & 9 & 10 & 11 & 12 & 13 & 14 & 15 & 16 & 17 & 18 & 19 & \\
\hline 1 & & 85.3 & 88.7 & 92.5 & 92.1 & 92.7 & 93.3 & 91.3 & 90.5 & 87.9 & 88.1 & 87.1 & 89.3 & 88.9 & 88.3 & 87.9 & 87.5 & 87.5 & 88.5 & 1 \\
\hline 2 & 14.8 & & 87.5 & 84.2 & 83.6 & 84.6 & \begin{tabular}{|l|l}
84.2 \\
\end{tabular} & 83.6 & 84.0 & 83.6 & 82.4 & 82.2 & 83.4 & 83.2 & 82.6 & 82.8 & \begin{tabular}{|l|l}
82.4 \\
\end{tabular} & 82.4 & \begin{tabular}{|l|}
82.8 \\
\end{tabular} & 2 \\
\hline 3 & 10.8 & 12.3 & & 89.5 & 89.3 & 89.1 & 89.5 & 87.7 & 89.3 & 87.1 & 87.1 & 86.3 & 87.5 & 87.5 & 87.3 & \begin{tabular}{|l|l}
87.1 \\
\end{tabular} & 86.5 & 86.5 & 87.9 & 3 \\
\hline 4 & 6.4 & 16.5 & 10.1 & & 98.2 & 93.3 & \begin{tabular}{|l}
93.3 \\
\end{tabular} & 91.3 & 90.7 & 87.9 & 88.1 & 87.9 & 89.3 & 88.9 & 88.3 & 87.9 & \begin{tabular}{|l}
87.7 \\
\end{tabular} & 87.7 & 88.9 & 4 \\
\hline 5 & 6.9 & 17.2 & 10.3 & 0.8 & & 92.9 & \begin{tabular}{|l}
93.1 \\
\end{tabular} & 91.1 & 90.5 & 87.7 & 88.1 & 87.7 & 89.1 & 88.7 & 88.1 & 87.7 & \begin{tabular}{|l|}
87.5 \\
\end{tabular} & 87.5 & 88.7 & 5 \\
\hline 6 & 6.0 & 15.5 & 10.4 & 5.5 & 6.0 & & 93.1 & 90.9 & 91.3 & 88.3 & 87.9 & 87.1 & 89.3 & 88.7 & 88.1 & 87.9 & \begin{tabular}{|l|l}
87.3 \\
\end{tabular} & 87.3 & \begin{tabular}{|l|l|}
88.7 \\
\end{tabular} & 6 \\
\hline 7 & 5.5 & 16.3 & 10.1 & 5.8 & 6.0 & 5.8 & & 92.7 & 92.7 & 89.3 & 89.1 & 89.3 & 90.9 & 90.5 & 89.9 & 89.5 & 89.5 & 89.5 & 90.3 & 7 \\
\hline 8 & 7.8 & 17.2 & 12.2 & 8.0 & 8.2 & 8.3 & 6.4 & & 95.8 & 92.5 & 92.3 & 91.7 & 94.3 & 93.7 & 92.5 & 92.5 & 91.7 & 91.7 & 92.7 & 8 \\
\hline 9 & 8.7 & 16.9 & 10.5 & 8.9 & 9.1 & 7.8 & 6.4 & 3.3 & & 93.7 & 93.3 & 93.1 & 95.8 & 95.2 & 93.9 & 93.7 & \begin{tabular}{|l}
93.1 \\
\end{tabular} & 93.1 & 93.7 & 9 \\
\hline 10 & 11.8 & 17.5 & 13.2 & 12.2 & 12.5 & \begin{tabular}{|l|l}
11.3 \\
\end{tabular} & 10.3 & 6.9 & 5.9 & & 98.4 & 95.2 & 96.2 & \begin{tabular}{|l|}
96.8 \\
\end{tabular} & 97.4 & 97.8 & 94.9 & 94.9 & 97.6 & 10 \\
\hline 11 & 11.5 & 19.0 & 13.2 & 12.0 & 12.0 & \begin{tabular}{|l|l|}
11.8 \\
\end{tabular} & 10.6 & 7.1 & 6.4 & 1.4 & & 95.4 & 96.0 & 96.8 & 97.4 & 98.2 & 94.9 & 94.9 & 97.6 & 11 \\
\hline 12 & 12.8 & 19.3 & 14.2 & 12.2 & 12.5 & 12.8 & 10.3 & 7.8 & 6.6 & 4.6 & 4.4 & & 95.2 & 95.8 & 95.6 & 95.6 & 97.6 & 97.6 & 95.8 & 12 \\
\hline 13 & 10.1 & 17.7 & 12.5 & 10.5 & 10.8 & 10.1 & 8.5 & 4.9 & 3.6 & 3.1 & 3.3 & 4.2 & & 97.8 & 96.2 & 96.0 & 94.9 & 94.9 & \begin{tabular}{|l|}
96.2 \\
\end{tabular} & 13 \\
\hline 14 & 10.6 & 18.0 & 12.7 & 11.0 & 11.3 & 10.8 & 8.9 & 5.5 & 4.4 & 2.7 & 2.7 & 3.8 & 1.4 & & 97.2 & 97.0 & 95.8 & 95.8 & 97.0 & 14 \\
\hline 15 & 11.3 & 18.8 & 12.9 & 11.7 & 12.0 & 11.5 & 9.6 & 6.9 & 5.7 & 2.3 & 2.3 & 4.2 & 3.1 & 2.3 & & 97.8 & 95.6 & 95.6 & 97.8 & 15 \\
\hline 16 & 11.8 & 18.5 & 13.2 & 12.2 & 12.5 & 11.8 & 10.1 & 6.9 & 5.9 & 2.1 & 1.6 & 4.2 & 3.3 & 2.5 & 1.9 & & 95.6 & 95.6 & 97.2 & 16 \\
\hline 17 & 12.3 & 19.0 & 13.9 & 12.5 & 12.7 & 12.5 & 10.1 & 7.8 & 6.6 & 4.8 & 4.8 & 2.1 & 4.4 & 3.8 & 4.2 & 4.2 & & 99.6 & 95.8 & 17 \\
\hline 18 & 12.3 & 19.0 & 13.9 & 12.5 & 12.7 & 12.5 & \begin{tabular}{|l}
10.1 \\
\end{tabular} & 7.8 & 6.6 & 4.8 & 4.8 & 2.1 & 4.4 & 3.8 & 4.2 & 4.2 & 0.0 & & 95.8 & 18 \\
\hline \multirow[t]{2}{*}{19} & 11.1 & 18.5 & 12.2 & 11.0 & 11.3 & 10.8 & $\begin{array}{l}9.2 \\
\end{array}$ & 6.6 & 5.9 & 2.1 & 2.1 & 4.0 & 3.1 & 2.5 & 1.9 & 2.5 & 4.0 & 4.0 & & 19 \\
\hline & 1 & 2 & 3 & 4 & 5 & 6 & 7 & 8 & 9 & 10 & 11 & 12 & 13 & 14 & 15 & 16 & 17 & 18 & 19 & \\
\hline
\end{tabular}

A-Quail-HongKong-G1-97 A-duck-HongKong-Y439-1997 A-chicken-HongKong-G9-1997 A-chicken-Israel-421201-2004 A-chicken-Israel-178-2006 A-Chicken-Iran-TH81-2002 A-chicken-Dubai-338-2001 A-chicken-Saudi A-chicken-Israel-1067-2010 A-chicken-FW1-2020 A-chicken-FW2-2020 A-chciken-FW3-2020 A-chicken-Egypt-2-2014 A-chicken-Egypt-7-2015 A-chicken-Egypt-v621-2018 A-chicken-Egypt-V4001-2018 A-chicken-Egypt-V2630-2019 A-chicken-Egypt-V2633-2019 A-chicken-Egypt-V2692-2019

\section{Figure 4}

Amino acid identities and divergence of HA gene of H9N2 viruses compared to other selected strains and vaccinal strains. FN: Amino acid identity of HA gene of H9N2 viruses showed that closely related to other Egyptian strains with identities of $94.9-98.2 \%$. 


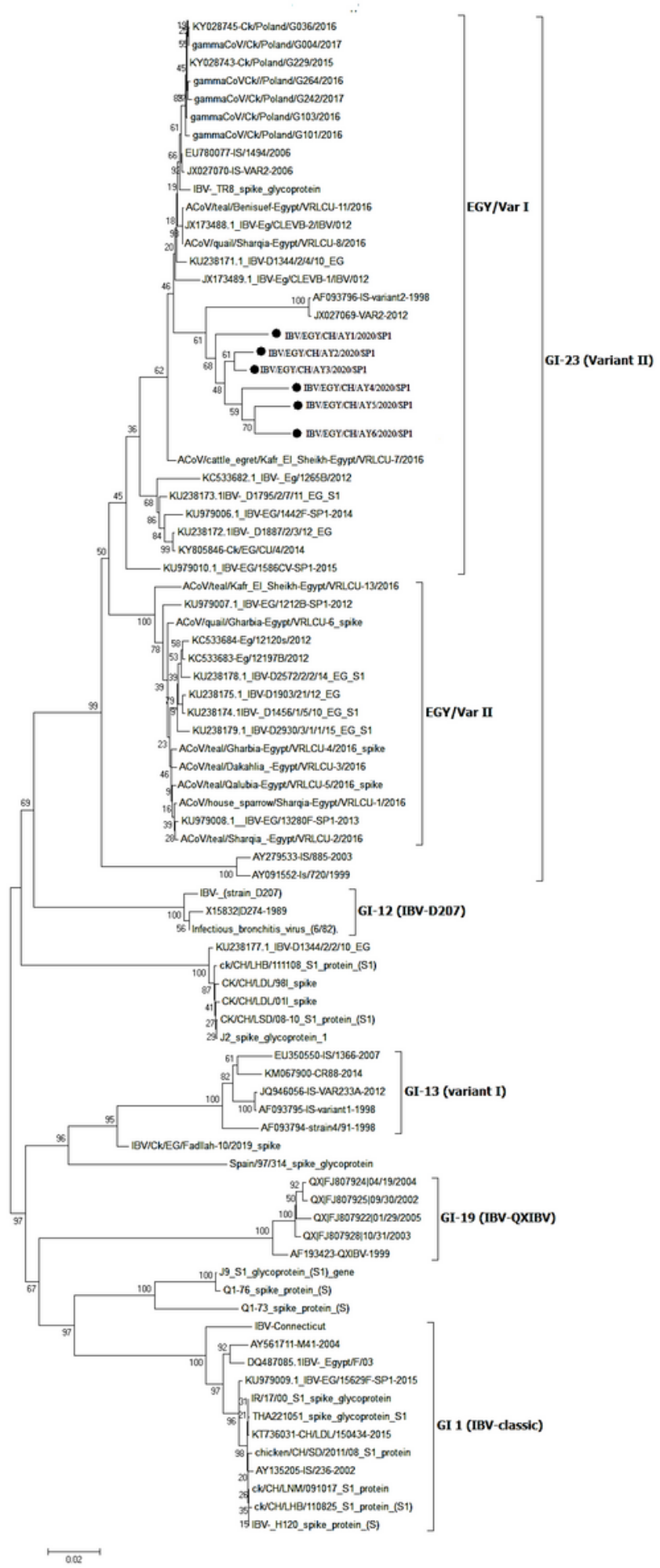

Figure 5

Phylogenetic tree of partial S1 gene of IBV. FN: The figure shows the phylogenitic analysis of HA gene of AIV H9N2 reveling that all Egyptian strains cluster were cluster to clad GI23 (Egy Var I). The IBV viruses in our study are indicated with a black dot. 
HVRl (60-88)

cu-4

Eg-CLEVB-2-IBV-012

IBV-Eg-CLEVB-1-IBV-012

IVB-Eg-CLEVB-2-012

IBV-EG-1586CV-SP1-2015

IBV-EG-13280F-SP1-2013

IBV-EG-1212B-SP1-2012

IBV-EG-1442F-SP1-2014

IBV-D2 930-3-1-1-15

IBV-D2572-2-2-14 EG

IBV-D1903-21-12

IBV-D1456-1-5-10

IBV-D1795-2-7-11

IBV-D1887-2-3-12

IBV-D1344-2-4-10

IBV-EGY-CH-AY1-2020

IBV-EGY-CH-AY2-2020

IBV-EGY-CH-AY3-2020

IBV-EGY-CH-AY 4-2020

IBV-EGY-CH-AY5-2020

IBV-EGY-CH-AY 6-2020
SG CCTAGSIYWSKNESASSVAMTAPDT

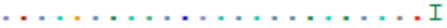

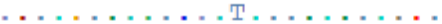

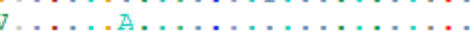

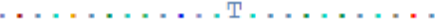

$\ldots . . . . . . . . . .$.

$\ldots . . . . . . . . .$.

$\ldots . . . . . . . . . . \mathrm{AN}$

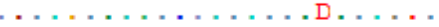

$\ldots . . . . . . . . . \mathrm{CN}$

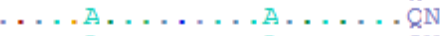

$\ldots . . . . . . . . . . .$.

$\ldots . . . . . . . . .$.

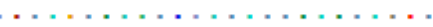

$\ldots \ldots \ldots \ldots$

$\ldots \ldots \ldots \ldots \ldots \ldots \ldots$

T $\ldots . . . . V_{\text {. }}$

S.............. V.

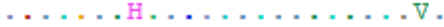

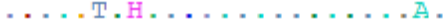

............... . . V.

S...T.H.......... V.
HVR2 (115-149)

YKNGQGSCPLTGLIPQNHIRISAMKNSSI

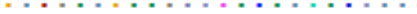

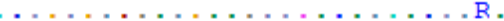

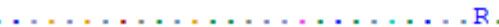

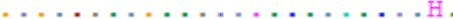

.SSS......M...HY.....R.N.

. SSS.........YY.....R.N.

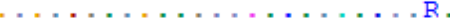

SSSE...............R.N. .

S.S.....M...Y.....R.N.

.SSS .....M...Y.....R.N. .

.SSS .........YY.....R.N.

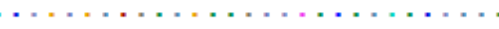

$\ldots \ldots \ldots \ldots \ldots$

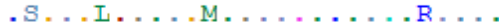

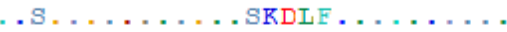

.S..........SKDLF.........

.H. ....I. . . . HL . . . . . H.

.S... . . . . KD . . . . . . H.

. . . . . . SKDL.... . .

\section{Figure 6}

Amino acid mutation in HVRS in S1 gene of IBV. FN: The HVR1 had 3,4,2 A.A. mutations in three, two and one samples in this study respectively. The HVRII had 7A.A. mutation in all viruses except two viruses had 6 and 4 mutations.

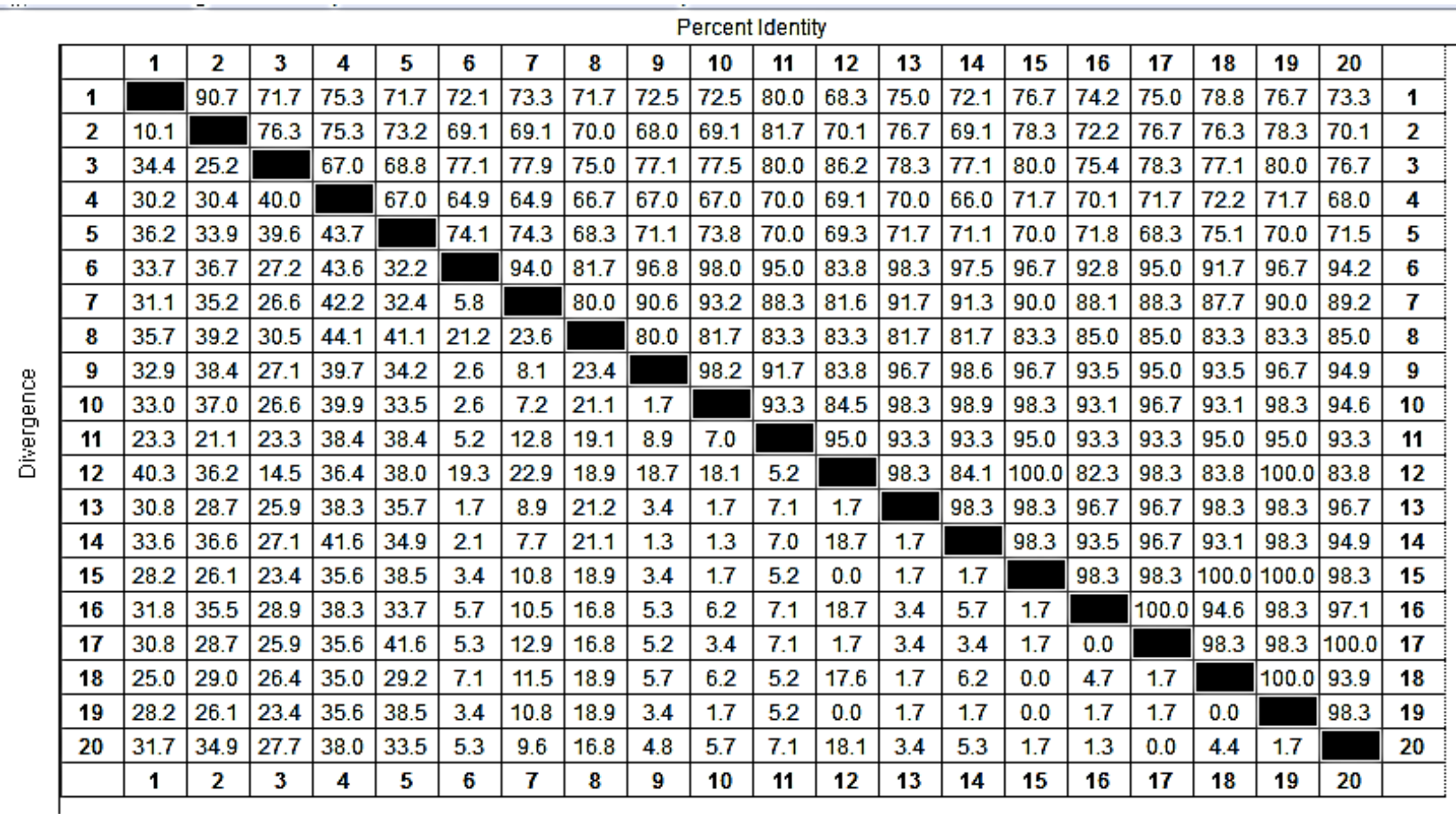

IBV-H120

IBV-M41

IBV-D207

IBV-QXIF

IBV-UK-4-91

IBV-IS-1494-06

IBV-VAR2

IBV-IS-885

IBV-cu-4

IBV-EG-CLEVB-1

IBV-EG-13280F

IBV-EG-1212B

IBV-EG-1442F

IBV-D1344-2-4-10

IBV-EGY-AY1-2020

IBV-EGY-AY2-2020

IBV-EGY-AY3-2020

IBV-EGY-AY4-2020

IBV-EGY-AY5-2020

IBV-EGY-AY6-2020

\section{Figure 7}

Amino acid identities and divergence of partial S1 gene of IBV sequenced viruses compared to other selected strains and vaccinal strains. FN: Amino acid identity of partial S1 gene of IBV viruses showed 
that A.A. identity percent of Egyptian IBV strain in this study ranged from $68.3 \%-78.8 \%$ with $\mathrm{H} 120, \mathrm{M} 41$, 4/91vaccine strains. 